Prepared for the U.S. Department of Energy

under Contract DE-AC05-76RL01830

\title{
Initial Risk Analysis and Decision Making Framework
}

\author{
DW Engel
}

February 2012

Pacific Northwest

NATIONAL LABORATORY

Proudly Operated by Battelle Since 1965 


\title{
DISCLAIMER
}

This report was prepared as an account of work sponsored by an agency of the United States Government. Neither the United States Government nor any agency thereof, nor Battelle Memorial Institute, nor any of their employees, makes any warranty, express or implied, or assumes any legal liability or responsibility for the accuracy, completeness, or usefulness of any information, apparatus, product, or process disclosed, or represents that its use would not infringe privately owned rights. Reference herein to any specific commercial product, process, or service by trade name, trademark, manufacturer, or otherwise does not necessarily constitute or imply its endorsement, recommendation, or favoring by the United States Government or any agency thereof, or Battelle Memorial Institute. The views and opinions of authors expressed herein do not necessarily state or reflect those of the United States Government or any agency thereof.

\author{
PACIFIC NORTHWEST NATIONAL LABORATORY \\ operated by \\ BATTELLE \\ for the \\ UNITED STATES DEPARTMENT OF ENERGY \\ under Contract DE-AC05-76RL01830
}

Printed in the United States of America
Available to DOE and DOE contractors from the Office of Scientific and Technical Information,
P.O. Box 62, Oak Ridge, TN 37831-0062;
ph: (865) 576-8401
fax: $(865)$ 576-5728
email: reports@adonis.osti.gov

\begin{abstract}
Available to the public from the National Technical Information Service, U.S. Department of Commerce, 5285 Port Royal Rd., Springfield, VA 22161 ph: (800) 553-6847 fax: $(703) 605-6900$ email: orders@ntis.fedworld.gov online ordering: http://www.ntis.gov/ordering.htm
\end{abstract}

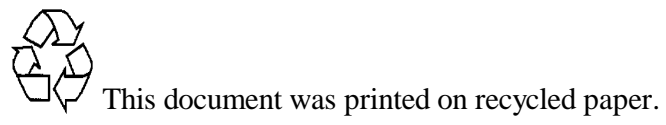




\section{Initial Risk Analysis and Decision Making Framework}

DW Engel

February 2012

Prepared for

the U.S. Department of Energy

under Contract DE-AC05-76RL01830

Pacific Northwest National Laboratory

Richland, Washington 99352 



\section{Contents}

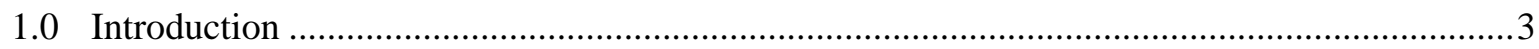

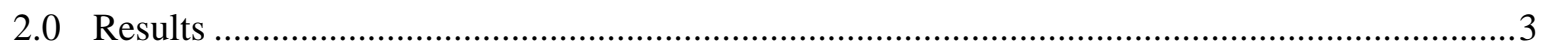

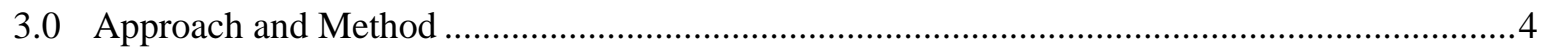

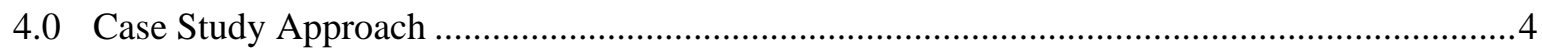

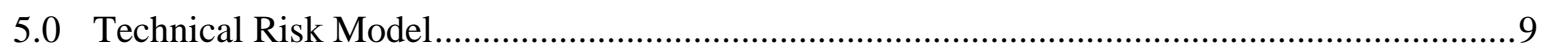

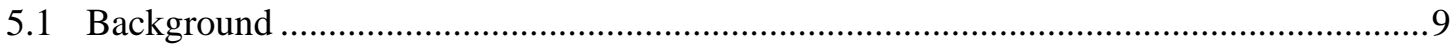

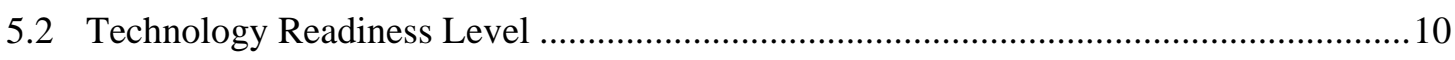

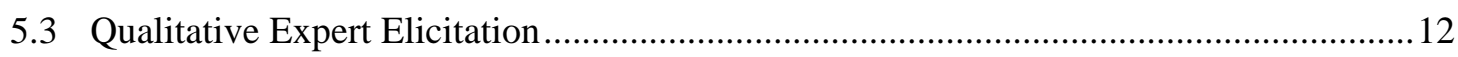

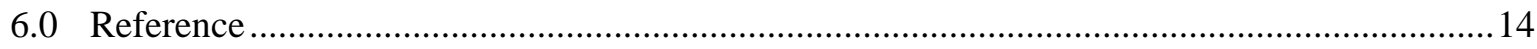

\section{Figures}

Figure 1 Coal plant parameters (factors): common to Cases A and B ........................................

Figure 2 CC system specific parameters: changed under Cases A and B ....................................

Figure 4 Discounted net present value of net receipts: Case A (red bar) versus Case B ................. 8

Figure 5 Discounted net present value of net receipts: Case A (red bar) versus Case B .................. 9

Figure 6 Information flow for the CCSI decision making framework........................................10

Figure 7 Qualitative risk contribution tree showing categorical pillars of Technical, Economic and Regulatory/Societal concerns. Sub topics illustrate a taxonomy for further refinement of each topic.

\section{Tables}

Table 1 Initial financial, operating, and market assumptions....................................................6

Table 2 Initial distributions of the five random factors ...............................................................

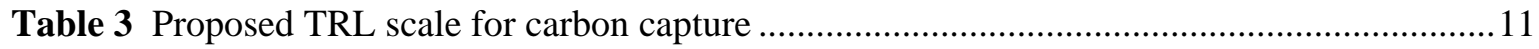

Table 4 Sample TRL-3 check list to evaluate a technology maturity ..........................................12

Table 5 Sample of qualitative elicitation form for collecting expert opinion on topical risk

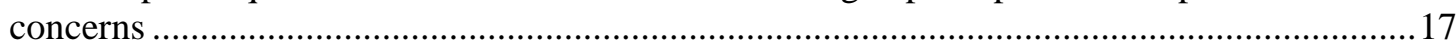

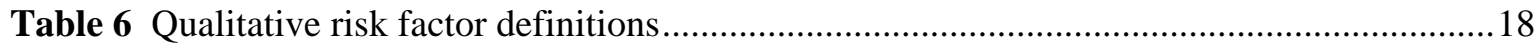

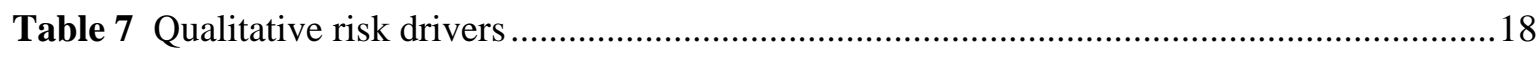




\section{Introduction}

Commercialization of new carbon capture simulation initiative (CCSI) technology will include two key elements of risk management, namely, technical risk (will process and plant performance be effective, safe, and reliable) and enterprise risk (can project losses and costs be controlled within the constraints of market demand to maintain profitability and investor confidence). Both of these elements of risk are incorporated into the risk analysis subtask of Task 7. Thus far, this subtask has developed a prototype demonstration tool that quantifies risk based on the expected profitability of expenditures when retrofitting carbon capture technology on a stylized $650 \mathrm{MW}$ pulverized coal electric power generator. The prototype is based on the selection of specific technical and financial factors believed to be important determinants of the expected profitability of carbon capture, subject to uncertainty. The uncertainty surrounding the technical performance and financial variables selected thus far is propagated in a model that calculates the expected profitability of investments in carbon capture and measures risk in terms of variability in expected net returns from these investments. Given the preliminary nature of the results of this prototype, additional work is required to expand the scope of the model to include additional risk factors, additional information on extant and proposed risk factors, the results of a qualitative risk factor elicitation process, and feedback from utilities and other interested parties involved in the carbon capture project. Additional information on proposed distributions of these risk factors will be integrated into a commercial implementation framework for the purpose of a comparative technology investment analysis.

\subsection{Results}

Thus far, the key accomplishment of this subtask is to illustrate risk attribute propagation through a financial balance sheet that incorporates variable technological features, lifecycle costs and other factors related to carbon capture. The significance of this subtask is that it provides a case study for illustrating information flow from quantitative and qualitative risk factor assignment and uncertainty quantification (UQ) from other CCSI tasks into familiar decision metrics like 30-year net present value, and it incorporates probabilistic decision making for eliciting industry feedback.

Summarized here are some of the key results observed from the prototype risk analysis tool. These specific results are meant only to illustrate the utility of the prototype risk analysis tool for integrating and comparing the impacts of diverse sources of uncertainty. The results could change significantly as risk factors, uncertainties and new risk metrics are considered based on integration of data and methods from the other tasks and on industry feedback. As explained later, many of these results are gleaned by statistically compiling the results of several thousand calculations that each represents one independent technology performance and investment scenario.

- One can afford to double or triple the construction cost of the carbon capture (CC) system if it means reducing its parasitic power significantly, increasing its capture percentage or lowering its operating cost - and - to a lesser degree, keeping the CC system duty factor penalty low (any decrease in duty factor due to the CC retrofit).

- One can afford to give up some on the CC duty factor penalty (let the penalty increase) if it means lowering the parasitic power requirements or the CC system operating costs.

- The CC option is competitive with a no capture baseline in less than $1 \%$ of all random scenarios, but with more optimistic assumptions for the distribution of possible parasitic power and CC operating costs, CC can be competitive $15 \%-20 \%$ of the time.

- All of these results, including the likelihood of CC being competitive with the non-CC baseline are sensitive to the assumption for carbon tax (nominally \$25/tonne). 
Initial Risk Analysis and Decision Making Framework

- A carbon tax of $\$ 45 /$ tonne represents the point where an equal number of cases are better and worse than the non-CC baseline.

Again, it must be emphasized that these results are illustrative only, to demonstrate the utility of the tool being developed to assess risk based on key technical and financial factors that will evolve as the tool is improved and integration with the other tasks and the industry partners is fully achieved.

\subsection{Approach and Method}

The approach requires translating technical and financial risk factors, along with uncertainties, into measures that can be included in estimating variability in expected financial returns, which is the principal metric used in this financial risk analysis. For a typical electric generating unit without carbon capture, construction costs will be incurred during the first few years of the life cycle, operations and maintenance (O\&M) expenditures will be incurred and receipts will accrue over each year of operations once construction of the plant is completed. If the plant is retrofitted to capture carbon sometime during its useful life, generation will be interrupted temporarily, additional construction expenditures will be incurred, and additional O\&M expenditures will be incurred once the retrofit is completed. All of these factors will affect the amount and timing of plant expenditures and revenues over the life cycle of the plant and, over the life cycle of the utility plant with a carbon capture retrofit, will affect the net profitability of the plant. In order to aggregate these revenue and expenditures into a single metric, these annual estimates of revenues and expenditures need to be converted to a common base year. This conversion is done through discounting, which applies an adjustment factor (usually expressed as an interest rate called the discount rate) to revenues and expenditures in each year. For each year, discounted net receipts (revenues less expenditures, discounted) are added up into a final discounted net receipt

The formula for the discounted net present value (NPV) is given by the following:

$$
N P V=\sum_{t=1}^{T} \frac{1}{(1+r)^{t}}\left[R_{t}-C_{t}\right]
$$

where $t$ indicates each year and $T$ is the total number of years in the life cycle (e.g., 30-years), $\mathrm{r}$ is the discount rate, $R_{t}$ is revenues in year $t$, and $C_{t}$ is expenditures in year $t$.

For this analysis, risk is defined as variability in the discounted net present value of receipts, and variability is propagated by uncertainty with respect to different technical attributes, revenue and cost estimates.

\subsection{Case Study Approach}

The initial demonstration of this methodology involved creating a baseline net present value calculation without carbon capture (Case A) and comparing that to an alterative net present value calculation with carbon capture retrofit (Case B). For Case B, NPV estimates were made given a distribution of values for selected factors that vary due to risk and uncertainty. Once this methodology is refined, it can be used to identify the best candidate factors for risk retirement and can be used to compare multiple carbon capture alternatives, instead of just comparing one carbon capture option to one "no carbon capture" scenario. 
The following discussion explains four steps that should be understood conceptually before attempting to interpret findings of the model. Conceptual understanding of these steps will also facilitate recommendations for refinement of the assumptions and expansion of the methods to alternative metrics of interest. It should be noted that the present model is evaluated in the familiar format of an Excel spreadsheet that can be made available to interested users and collaborators.

The first step of this demonstration is to determine a set of financial and technical factors common to both Cases A and B. These factors are shown in Figure 1. These factors are assumed to be known with certainty, even though they can vary throughout the life cycle of the plant. Subsequent analysis will add many of these variables to the list of factors allowed to vary according to some distribution of uncertainty.

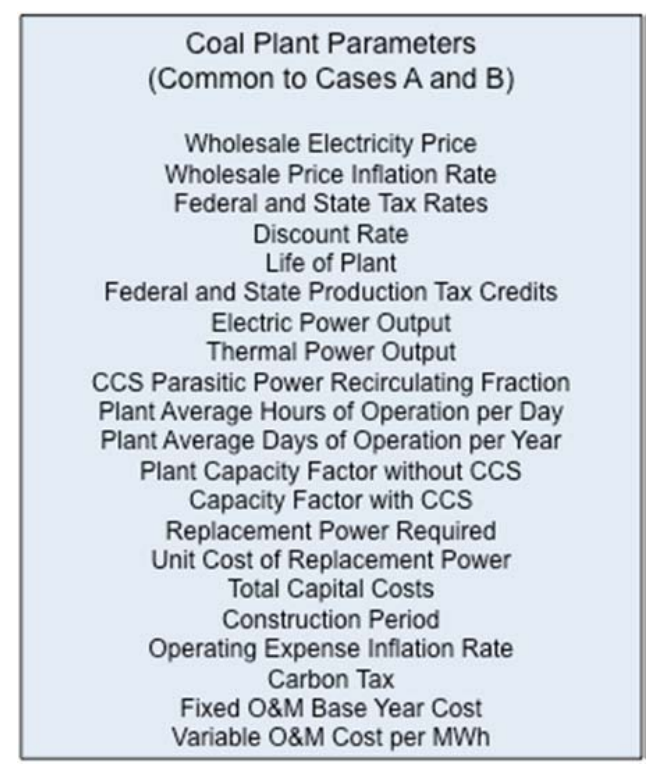

Figure 1 Coal plant parameters (factors): common to Cases A and B

The second step of the demonstration is to determine which set of factors would be subject to uncertainty. These factors are shown in Figure 2. The factors in Figure 2 were selected to demonstrate this methodology since they specifically characterize some of the key technical and financial performance measures of the carbon capture system. The initial nominal values of these variables (factors) were determined from the U.S. Department of Energy and other publications. The initial ranges were determined judgmentally. As the project progresses, additional factors will be included in the financial risk assessment in order to capture a fuller range of technical and financial uncertainties relating to carbon capture.

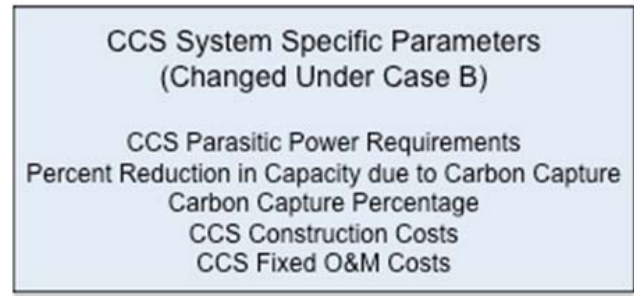

Figure 2 CC system specific parameters: changed under Cases A and B 
Table 1 shows the initial assumptions used in the Case A baseline. The variables whose initial values are presented in blue are user-selectable. For example, if the user wants to reduce the duty cycle of the plant, they can reduce the Plant Average Hours of Operation per Day variable from the initial value of 20 hours to some lower value. This will recalculate the discounted net present value for both the Case A baseline and the Case B scenario. In addition, the impacts of some of these factors on the NPV calculation will be affected by timing; construction expenditures, for example, could occur over a five-year period instead of the default period of two years. In this case, the timing of construction costs, as well as the timing of revenues from generation, will change and this change would be captured in the revised NPV calculation.

Table 1 Initial financial, operating, and market assumptions

\begin{tabular}{|c|c|c|}
\hline Rate, Tax and Growth Assumptions & Value & Units \\
\hline Utility PPA per MWh & 60 & \$ per MWh \\
\hline PPA Inflation Rate & $1.5 \%$ & Percent \\
\hline Federal tax rate & $35 \%$ & Percent \\
\hline State tax rate & $7.0 \%$ & Percent \\
\hline Discount rate & $7.0 \%$ & Percent \\
\hline Tax life of plant & 30 & Years \\
\hline Federal PTC & $0.0 \%$ & Percent \\
\hline Federal ITC & $30.0 \%$ & Percent \\
\hline State ITC & $7.0 \%$ & Percent \\
\hline State PTC multiplier & 1 & Units \\
\hline Electric v. Thermal Power Production & Value & Units \\
\hline Electric Power Output & 650 & MWe \\
\hline Thermal Power Output & 1,759 & MWth \\
\hline Replacement Power & Value & Units \\
\hline CCS Parasitic Power Requirements & 210 & MWe \\
\hline CCS Parasitic Power Recirculating Fraction & 0.3231 & - \\
\hline Plant Average Hours of Operation per Day & 20 & hours/day \\
\hline Plant Average Days of Operation per Year & 350 & days/year \\
\hline Plant Capacity Factor without CCS & 0.799 & - \\
\hline Drop in Duty Factor due to CCS & $5.0 \%$ & percent \\
\hline Duty Factor with CCS & 0.759 & - \\
\hline Replacement Power Required & 236 & MWe \\
\hline Unit Cost of Replacement Power & 60.0 & \$/MWe \\
\hline Plant Construction Expenses & Value & Units \\
\hline Total Capital Costs & 2 & \$B \\
\hline Construction Period & 2 & Years \\
\hline Operating Expenses & Value & Units \\
\hline Operating Expense Inflation Rate & $1.5 \%$ & Percent \\
\hline Carbon Capture Percentage & $90 \%$ & Percent \\
\hline Carbon Tax & 25 & $\$$ per ton \\
\hline Fixed O\&M Base Year Cost & 23 & $\$ \mathrm{M}$ \\
\hline Variable O\&M Cost per mWh & 4.25 & \$ per MWh \\
\hline Carbon Capture Retrofit & Value & Units \\
\hline CCS Construction Costs & 1.6 & \$B \\
\hline CCS Fixed O\&M Costs & 50 & $\$ M / y e a r$ \\
\hline Variable O\&M Costs & 0.0087 & $\$$ per $\mathrm{kW}$ \\
\hline Construction Period & 2 & years \\
\hline
\end{tabular}


The third step is to assign ranges to the initial set of five variables (CCS Parasitic Power Requirements, Drop in Duty Due to CCS, Carbon Capture Percentage, CCS Construction Costs, and CCS Fixed O\&M Costs) that are allowed to vary randomly in this version of the model. The variables whose values are presented in black and bold in Table 1 are ones that can have their distribution changed by the user. In this version of the model, variation in these factors is incorporated into the financial risk analysis by changing the range (i.e., the minimum and maximum value) of the variable of interest. Table 2 shows the nominal value of each of the initial set of these variables, and their assumed low and high values.

Table 2 Initial distributions of the five random factors

\begin{tabular}{|l|c|c|c|c|c|}
\hline Replacement Power & Value & Units & Min & Max & Average \\
\hline CCS Parasitic Power Requirements & 210 & MWe & 160 & 260 & 210 \\
\hline Drop in Duty Factor due to CCS & $5.0 \%$ & percent & $0 \%$ & $10 \%$ & $5.0 \%$ \\
\hline & & & & & \\
\hline Operating Expenses & Value & Units & Min & Max & Average \\
\hline Carbon Capture Percentage & $90.0 \%$ & Percent & $85.0 \%$ & $95.0 \%$ & $90.0 \%$ \\
\hline & & & & & \\
\hline Carbon Capture Retrofit & Value & Units & Min & Max & Average \\
\hline CCS Construction Costs & 1.6 & \$B & 0.5 & 3.0 & 1.6 \\
\hline CCS Fixed O\&M Costs & 50 & \$M/year & 25.0 & 100.0 & 50.0 \\
\hline
\end{tabular}

The fourth step is to calculate alternative net discounted present values using Monte Carlo simulation methods incorporating 3000 cases and create a histogram that shows the distribution of discounted net present value estimates using the distributions for the five variables listed in Table 2. For purposes of this demonstration, we assume that these values are distributed uniformly, but subsequent analyses (based in part on the results of the UQ task) will allow for alternative statistical distributions (e.g., normal, lognormal and beta distributions). Under the assumed values in Tables 1 and 2, the resulting distribution of NPV is given in Figure 3. The distribution represents the binned estimated discounted present value of net receipts. The estimated discounted present value of net receipts given by the red bar is the Case A baseline estimate. The results of this comparison suggest that virtually all Case B discounted net present values are less than that which occurs under the Case A baseline. A small percentage of cases with carbon capture can have a higher discounted net present value for those random scenarios having higher revenues combined with lower costs, as well as higher duty factors, but these cases represent but a small number of possible cases (less than 5 percent).

To illustrate how the tool can be used for comparative analyses, consider the case where we shift the range on parasitic power by lowering the minimum and maximum values by one-half. Instead of a baseline parasitic power distribution range of 160MWe and 260MWe, we lower that range to 80MWe and 130MWe. In effect, this lessens parasitic power losses and should improve carbon capture relative to the baseline without carbon capture. Figure 4 illustrates that with lower parasitic power losses, the distribution of discounted net present values under carbon capture shifts to the right, with roughly 20 percent of the carbon capture cases exceeding the no-carbon-capture baseline. 


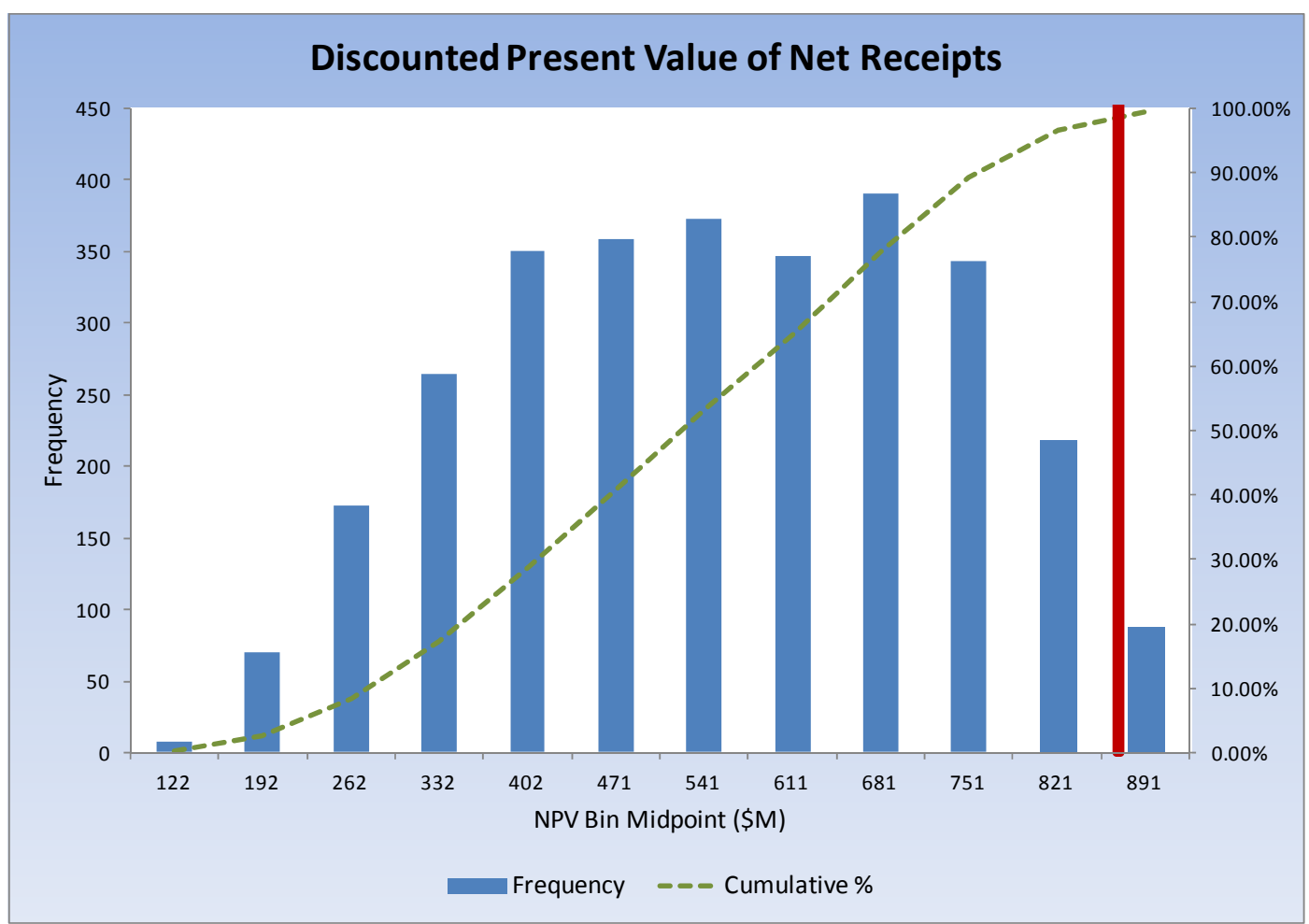

Figure 3 Discounted net present value of net receipts: Case A (red bar) versus Case B

This tool demonstrates one example of how risk attributes can propagate through a financial balance sheet that incorporates variable technological factors, lifecycle costs and other factors related to carbon capture. The significance of this subtask is that it provides a case study for illustrating information flow from risk factor assignment and uncertainty quantification (UQ) from other CCSI tasks into familiar decision metrics like 30-year net present value, and it incorporates probabilistic decision making for eliciting industry feedback. In addition, it presents risk propagation in a manner that will be accessible and understandable to the very audience (utility financial managers) that will be involved in making decisions on carbon capture investments.

A regression analysis was also performed to examine the relative importance of the five CC characteristics in determining the outcome of interest (in this case NPV). For the purposes of this illustration the carbon capture NPV is assumed to be made up of a linear combination of these characteristics and the resulting coefficients in the regression are indicative of the relative contribution of each of the five CC characteristics to NPV.

We have chosen NPV as the outcome of interest for this illustration of the tool but other outcomes could just as easily be used. 


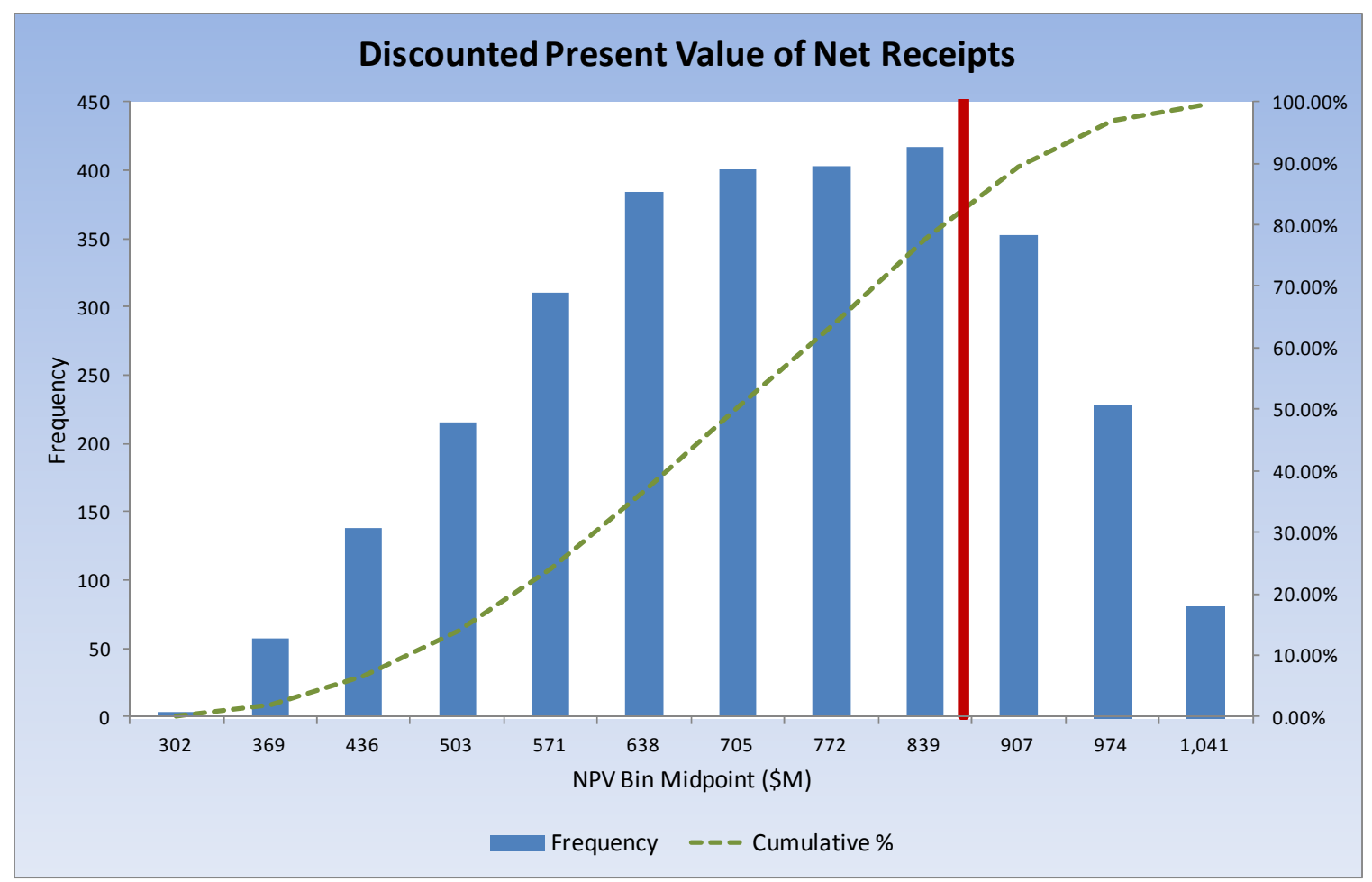

Figure 4 Discounted net present value of net receipts: Case A (red bar) versus Case B

Given the preliminary nature of the results of this prototype, additional work is required to expand the scope of the model to include additional risk factors, additional information on extant and proposed risk factors, the results of the risk factor elicitation process, and feedback from utilities and other interested parties involved in the carbon capture project.

\subsection{Technical Risk Model}

The Technical Risk Model will be a software system to estimate uncertainties and risks for the major technical components of a carbon capture system. To accomplish this task, we will develop a new (novel) Technology Readiness Level Uncertainty model and a Qualitative Elicitation Uncertainty model to be coupled with results from the Process Synthesis and Design Modeling team (Task 3) including estimated uncertainties (Task 6) to estimate the technical risks.

\subsection{Background}

For the development of the overall decision making framework, we will be utilizing a "top-down" approach, driven by our Life Cycle Business (Financial) Model (LCBM). Therefore, the components that feed directly into the LCBM will be key factors. We will need to identify the risk performance measures from these factors and identify needed uncertainties to be modeled by the Uncertainty Quantification team. The decision making framework will be based on the information flow shown in Figure 5. In this figure, the LCBM is represented by the Life Cycle Business Perspective, while the Technical Risk Model will couple the three risk models shown on the left side of the figure. 


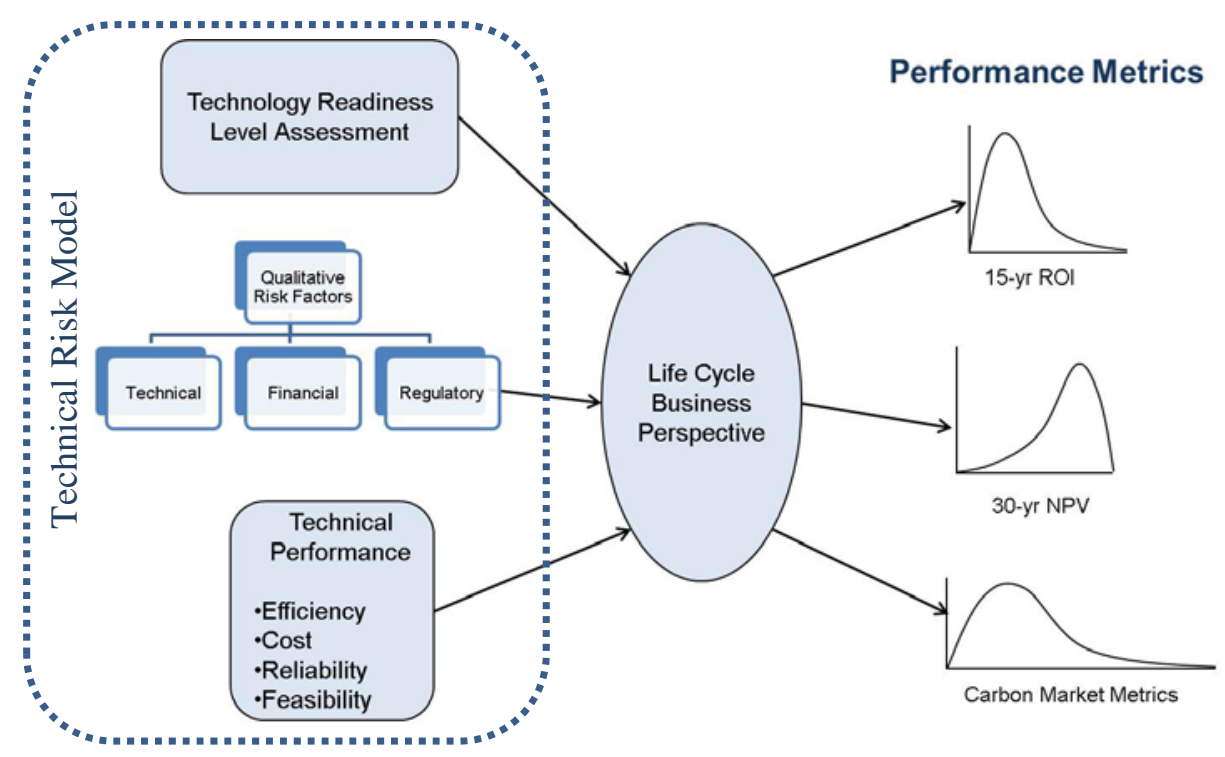

Figure 5 Information flow for the CCSI decision making framework

We define "technical risk" as the likelihood that a system will not reach its goals for performance, cost or schedule due to technology risks, to risks which arise in the integration of critical technologies and/or sub-systems dependent on them, or to the system integration. Technical risk denotes the risk that a project will fail to meet its performance criteria. In essence, Risk is the uncertainty that a product design will not satisfy desired technical requirements and the consequences thereof.

In FY11, a design of the LCBM was developed and a prototype system was created. Many inputs into this model are of the technical type and will be modeled using this new Technical Risk Model. Some of these parameters (Technical Performance shown in Figure 5) will come from the process synthesis and design modeling (Task 3), with uncertainties being simulated by the modeling team with input distributions and uncertainty analysis methods defined by the Uncertainty Quantification team (Task 6). The marginal distributions for these technical risk factors will then be input into the LCBM.

Other parameters will not be modeled by the Process Synthesis \& Design Modeling team. To estimate these parameters (including uncertainties), we identified two new modeling efforts:

- Technology Readiness Level (TRL) Risk Model, and

- Qualitative Expert Elicitation Risk Model.

\subsection{Technology Readiness Level}

Measuring a technology's maturity provides one measure that can be an indicator of program risk. As the GAO report states (GAO-10-675 2010), “Once a technology's readiness level has been established, the risks of including that technology in a product development can be assessed. Unlike S\&T projects, for which the main objective is to develop knowledge, a product development's objective is to deliver products that meet strict cost, schedule, and performance targets.” The report goes on to argue that a low level of readiness (low TRL) represents a high risk, because there are many unknowns that still need to be resolved in developing the technology. These unknowns create programmatic risk because, until they are satisfactorily resolved, we don't know whether the selected technology can meet the program's cost, schedule, and performance goals. The gap between the maturity of the technology and the product's requirements represents the risks or unknowns about the technology. 
The TRL is a measure used to assess the maturity of evolving technologies prior to incorporating the technology into a system/subsystem (Mankins 1995). The qualitative TRL can be used to roughly estimate the uncertainty bounds in a comparison of technologies (Mathews 2010). This methodology will be used to help quantify technical risks and used to accomplish the following objectives:

- yard stick to measure accelerated development against traditional development, and

- introduce uncertainty into framework of technical risk model.

To compare an accelerated development to a traditional development, the tradition development needs to be defined. Table 3 shows a proposed traditional maturity scale for this development. This table was developed by combining similar ideas developed by EPRI and the GAO (Freeman and Bhown 2011 and GAO-10-675 2010)

Table 3 Proposed TRL scale for carbon capture

\begin{tabular}{|c|l|l|}
\hline \multicolumn{2}{|c|}{ Technology Readiness Level (TRL) } \\
\hline 9 & Commercial operation in relevant environment & $\begin{array}{l}650 \mathrm{MW} \\
>100 \mathrm{MW}\end{array}$ \\
\hline 7 & Commercial demonstration, full scale deployment in final form & $10-50 \mathrm{MW}$ \\
\hline 6 & Fullem prototype in an operational environment & $1 \mathrm{MW}$ \\
\hline 5 & Component validation in relevant environment (coal plant) & $1 \mathrm{~kW}$ \\
\hline 3 & Component validation tests in laboratory environment & \\
2 & Fnalytical and experimental critical function proof-of-concept & \\
1 & Barmulation of application & \\
\hline
\end{tabular}

EPRI 2011 (Freeman and Bhown) \& GAO 2010

In order to access the maturity of a technology, a system for the assessment is needed. Such a system was developed by the U.S. Air Force (Nolte et al., 2003). This system contains a check list for each readiness level. An abbreviate example for the TRL-3 is shown in Table 4. For our purpose, we will modify the questions within the check list and apply them to the different technologies. 
Table 4 Sample TRL-3 check list to evaluate a technology maturity

\begin{tabular}{|l|l|}
\hline$\checkmark$ & Predictions of elements of technology capability validated by analytical studies \\
\hline$\checkmark$ & Mathematical and/or computer models and simulations are possible \\
\hline$\checkmark$ & Preliminary system performance characteristics and measures have been identified and estimated \\
\hline$\checkmark$ & Predictions of elements of technology capability validated by M\&S \\
\hline$\checkmark$ & Predictions of elements of technology capability validated by Lab experiments \\
\hline$\checkmark$ & Paper studies indicate that system components ought to work together \\
\hline$\checkmark$ & Scaling studies have been started \\
\hline$\checkmark$ & Existing software examined for possible reuse \\
\hline$\checkmark$ & Know limitations of presently available software (software analysis completed) \\
\hline$?$ & Scientific feasibility fully demonstrated \\
\hline$\checkmark$ & Analysis of present state of the art shows that technology fills a need \\
\hline$?$ & Risk areas identified in general terms \\
\hline$?$ & Risk mitigation strategies identified \\
\hline$\checkmark$ & Rudimentary best value analysis performed, not including cost factors \\
\hline
\end{tabular}

AFRL TRL Calculator, version 2.2 (abbreviated list)

Utilizing the results of the check list for each readiness level, an uncertainty model is being developed, which utilizes the following form:

Where the estimated TRL uncertainty bound can be calculated using algorithms developed by Mathews (Mathews 2009) and is the probability that a given technology is at a certain readiness level, estimated using the following binomial probability distribution:

This uncertainty estimate can then be used in the decision making model. In the uncertainty realm, you can think of this as a model uncertainty that can be access directly to the performance measure.

\subsection{Qualitative expert Elicitation}

As explained above, risks associated with new technology development and adoption can broadly be

$$
f(k ; n, p)=\left(\begin{array}{l}
n \\
k
\end{array}\right) p^{k}(1-p)^{n-k}
$$

described by the residual uncertainties involved with numerous factors such as performance, cost, reliability, etc. During initial development of a nascent technology, like carbon capture, it can be difficult to quantify the full spectrum of risk contributors, but it is always valuable to characterize and organize the concerns that are inevitably raised by various stakeholders. The process of enumeration and categorization is an important step towards systematic prioritization and ultimate resolution of the driving risk elements. The subtask of Qualitative Expert Elicitation attempts to leverage the diverse expertise of CCSI industry collaborators and national laboratory subject matter experts to capture the range of topical concerns and establish a format for pseudo quantitative ranking. The ranking schema will support comparative prioritization and will facilitate introduction of qualitative risk factors in the LCBM.

Many performance related risk factors like capture efficiency and plant-performance impacts are presently being simulated by other working groups within CCSI. Computational variables that are subject to uncertainty are amenable to propagation and diagnostic analysis using tools developed by the 
Initial Risk Analysis and Decision Making Framework

Uncertainty Quantification (UQ) team. Other variables of concern are much more qualitative in nature. The following questions illustrate qualitative concerns that have real impacts on the decision processes involved with development, adoption, and implementation of a carbon capture technology:

Does engineering infrastructure exist for design, fabrication, transportation, maintenance and supply of the proposed technology?

What public perception challenges may be associated with alternative capture technologies?

What degree of confidence has been established in the accuracy of physical simulations and their ability to predict transient behavior in experimental configurations?

What operational hazards and challenges are associated with industrial implementation of the proposed technology?

Is there a consensus opinion of technology maturity that will stimulate contractual engineering performance guarantees and capital investment loans at competitive rates?

Factors such as these directly influence many of the parameters inherent to the LCBM, and it is essential to capture qualitative judgment as well as computational uncertainty in order to have a well-informed risk evaluation. Figure 6 illustrates a first attempt to define a taxonomy for qualitative risk categorization. The primary pillars of Technical, Economic and Regulatory/Societal concerns provide a suggestive structure for itemizing and associating various concerns expressed by a variety of stakeholders. Subtopics suggest a taxonomy for further refinement and elaboration of each issue into many deeper roots of this Technology Maturity "tree." Note that some subcategory contributors may appear in several of the branches, and duplication is okay.

The process of eliciting qualitative rankings for each of these topics is facilitated by the questionnaire illustrated in Table 5. This form is simply a tabular representation of the risk contribution tree in a topical outline format. A large population of carbon capture participants is asked to rank their level of concern (1-5) or skip each of the possible risk contribution factors for as many levels of the table as they have time for. This is also an opportunity to elicit additional concerns to add to the directory tree.

Qualitative risk level assignments are guided by the definitions provided in Table 6. Each category is assigned a level from 1-5 indicating low to high risk perception. In addition, the respondents are asked to provide a dominant reason for their ranking taken from the alphabetical options in Table 7, or provide their own comments to briefly explain the risk level assignment.

If a sufficient number of participants respond to the questionnaire, the spread of qualitative ratings can be used to define a multinomial probability distribution for each topic. The distributions can then be "rolled up,” or integrated, along each branch of the risk contribution tree to provide pseudo-quantitative input to the LCBM on various issues such as those itemized above. Specific linkages between the qualitative risk assessment and the LCBM have not yet been explicitly itemized, but the interface that is envisioned is completely compatible with the current demonstration framework and with UQ propagation methodology.

A formal elicitation of qualitative risk factors has not yet been performed, but the templates are prepared to canvas the participants of the September 26, 2001 Industrial Advisory Board meeting held in Morgantown, West Virginia. Greater value will be gained with an increasing number of participants and with increasing detail in the tree. One additional advantage of the elicitation will be that it provides a method of tracking the technology maturation process as more data are generated and more experimental configurations are simulated. In tandem with the TRL strategies outlined above, it is hoped that these 
complementary approaches will be useful in accelerating the consensus of technology maturity that is needed for wide-scale industry deployment of candidate carbon capture options.

\subsection{Reference}

Freeman, BC \& Bhown, AS, Assessment of the technology readiness of post-combustion CO2 capture technologies, Energy Procedia, 4, p.1791-1796, 2011.

Mathews, S, Valuing risky projects with real options. Research-Technology Management 52(5): 32-41, 2009.

Mankins, JC, Technology Readiness Levels: A White Paper, NASA, Office of Space Access and Technology, Advanced Concepts Office, 1995.

Nolte, WL, et al., Technology Readiness Level Calculator, Air Force Research Laboratory, presented at the NDIA Systems Engineering Conference, 2003.

United States General Accounting Office, Coal Power Plants: Opportunities Exist for DOE to Provide Better Information on the Maturity of Key Technologies to Reduce Carbon Dioxide Emissions, Washington D.C.: US GAO, GAO-10-675, 2010. 



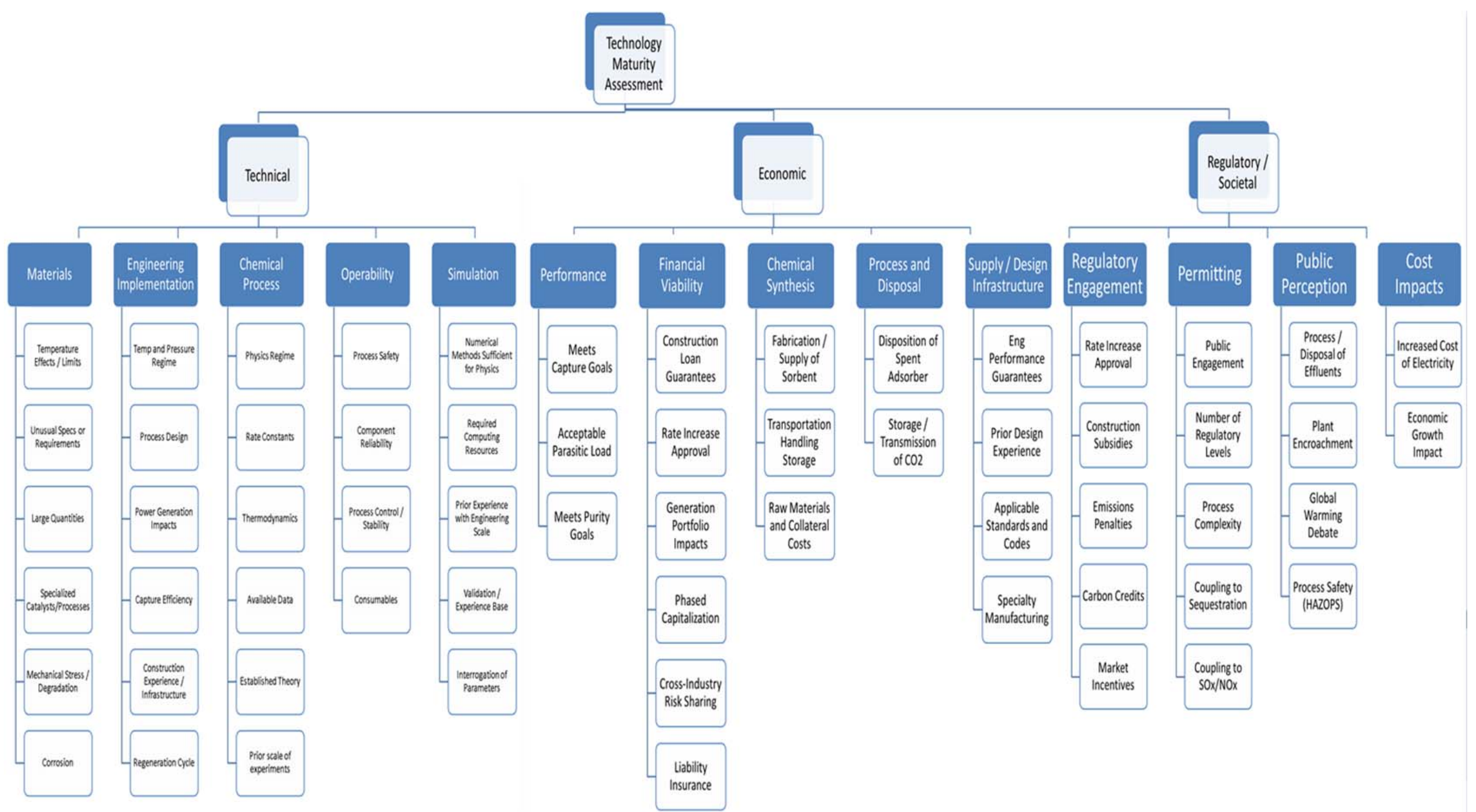

Figure 6 Qualitative risk contribution tree showing categorical pillars of Technical, Economic and Regulatory/Societal concerns. Sub topics illustrate a taxonomy for further refinement of each topic. 
Table 5 Sample of qualitative elicitation form for collecting expert opinion on topical risk concerns

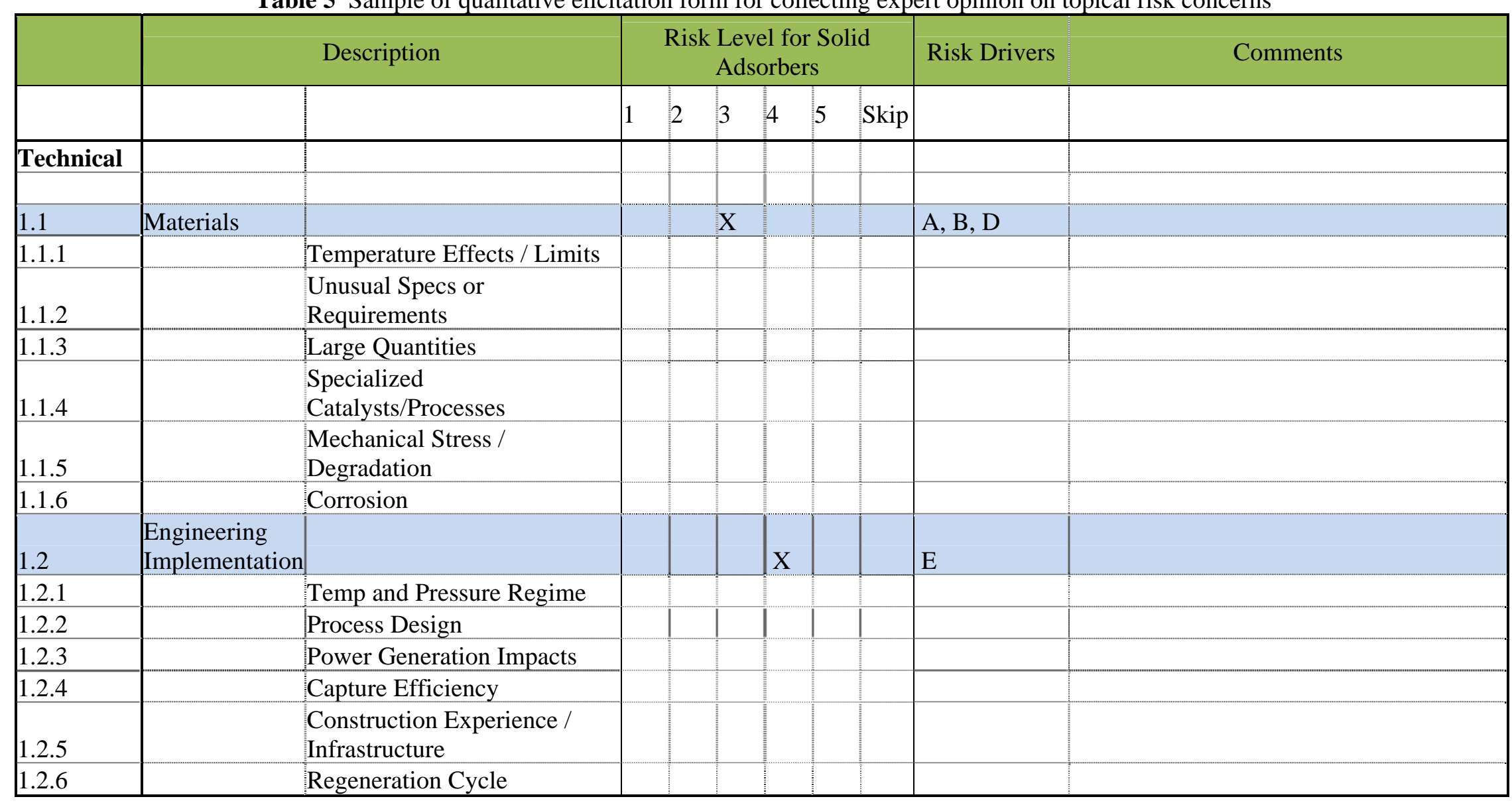


Table 6 Qualitative risk factor definitions

\begin{tabular}{|c|c|}
\hline \multicolumn{2}{|c|}{ Risk Levels } \\
\hline Level 1 & Risk Factor contributes little residual risk (issue is well understood and studied) \\
\hline Level 2 & Risk Factor contributes some residual risk (issue shows signs of success and acceptability, but retains uncertainties) \\
\hline Level 3 & Risk Factor represents legitimate concerns (issue shows systematic study, but lacks definitive conclusions) \\
\hline Level 4 & Risk Factor carries significant uncertainty and/or potential project impact (issue sparsely investigated to date) \\
\hline Level 5 & Risk Factor may dominate the project risk profile (issue is formative and as yet undemonstrated or unproven) \\
\hline
\end{tabular}

Table 7 Qualitative risk drivers

\begin{tabular}{|c|c|}
\hline \multicolumn{2}{|c|}{ Risk Drivers } \\
\hline A & Degree of maturity in terms of knowledge, understanding, or ability to develop \\
\hline B & External uncertainties in the areas of permitting, finance, or regulatory and public concerns \\
\hline C & Technical performance during tests or deployment, etc. \\
\hline D & Cost versus efficiency relative for use, manufacturability, operability, or other factors \\
\hline E & Incompatibility/Insufficiency of simulation tools relative to physics and engineering regime \\
\hline F & Does not seem to apply in this context \\
\hline
\end{tabular}





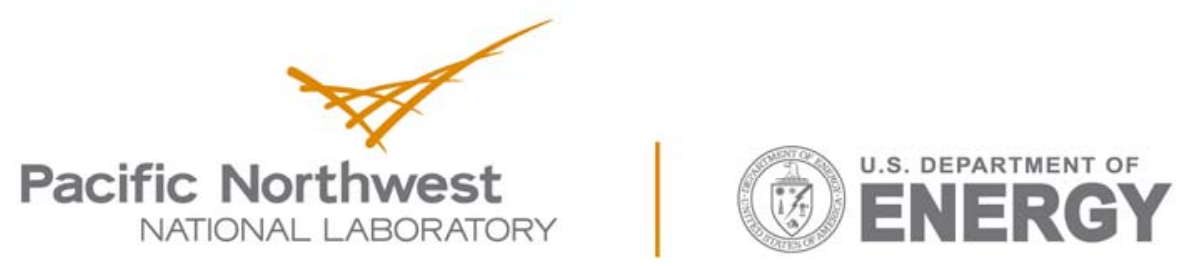

Proudly Operated by Battelle Since 1965

902 Battelle Boulevard

P.O. Box 999

Richland, WA 99352

1-888-375-PNNL (7665)

www.pnnl.gov 